\title{
FACTOR INFLUENCING LENGTH OF STAY (LOS) OF PATIENTS UNDERGOING BYPASS SURGERY AT SHAHEED MADANEE CARDIAC TEACHING HOSPITAL -TABRIZ - IRAN
}

\author{
Reza Gholi Vahidi ${ }^{1}$, Rahim Khodayari ${ }^{2}$, Shabnam lezadi ${ }^{3}$, Kamal Gholipour ${ }^{4}$
}

\begin{abstract}
Aim. This study aimed to study the effect of patients' and physician's characteristics as a predictor of length of stay (LOS) in patients undergoing coronary bypass surgery. Material and methods. This was a retrospective study conducted at Tabriz Shaheed Madanee Cardiac Teaching Hospital in Iran in 2010. The 349 patients who did undergo a bypass surgery during 2008-2010 were studied. Patients and physicians characteristic were collected from patients medical records using a researcher developed checklist. Independent Samples Test of ANOVA was conducted to compare LOS between categorical variables. Data was analyzed using the SPSS17 statistical package. Results. The mean age of the patients was 59.7 years. Overall average LOS was 15.58 (10.02) days. The findings of this study indicate that older patients stayed in the hospital for a significantly longer period than did younger patients. Patients' stay at the hospital was statistically significant and longer than assessed expected length of stay estimated by physicians $(P<0.05)$. Patient admitted to the hospital through emergency department and patients with no hospitalization history stayed longer in the hospital $(P \leq 0.01)$.). Early discharged patients and death cases also had a longer LOS ( $P \leq$ 0.01).Patient whose attending physicians were working in private sector, in addition to Shaheed Madanee Hospital and had higher level of education stayed longer than those whose physicians worked only at Shaheed Madanee Hospital $(P \leq 0.01)$.

Conclusion. Institutional characteristics - physicians practice both in private sector and public teaching hospital, physicians' level of education, discharge process guidelines, and admission protocols were most important factor in predicting LOS. The patient's hospitalization history whether patient was hospitalized before or not, was also a predictor.
\end{abstract}

Russ J Cardiol 2014, 4 (108), Engl.: 60-63

Key words: coronary arteries bypass surgery, Length of stay, Teaching Hospital.

${ }^{1}$ Associate Professor of Health Services Management, Tabriz Health Service Management Research Center, Department of Health Service Management, Faculty of Health Service Management and Medical Informatics, Tabriz University of Medical Sciences, Tabriz; ${ }^{2} \mathrm{PhD}$ candidate in Health policy, Faculty of Management and Medical Informatics. Science, Tehran University of Medical Sciences, Tehran; ${ }^{3}$ MSc of Health Services Management, Health Management and Economics Research Center, Iran University of Medical Sciences, Tehran; ${ }^{4} \mathrm{PhD}$ candidate in Health Services Management, Iranian Center of Excellence for Health Management, Faculty of Management and Medical Informatics, Student Research Committee, Tabriz University of Medical Sciences, Tabriz, Iran.

Corresponding author. Kamal Gholipour, Faculty of Management and Medical Informatics, Tabriz University of Medical Sciences, Attar Nishabouri Rd, Golgasht, EAZN 5166614711, Tabriz, Iran, Tel: +984113355952, Fax: +984113340634, e-mail: gholipourk@tbzmed.ac.ir

Received August 01, 2013

Revision received August 13, 2013.

Accepted August 20, 2013

\section{ФАКТОР, ВЛИЯЮЩИЙ НА ПРОДОЛЖИТЕЛЬНОСТЬ ПРЕБЫВАНИЯ (ПП) ПАЦИЕНТОВ, ПЕРЕНЕСШИХ ОПЕРАЦИИ ШУНТИРОВАНИЯ В КАРДИОЛОГИЧЕСКОЙ КЛИНИЧЕСКОЙ БОЛЬНИЦЕ SНАНЕЕD MADANEE -TEБРИЗ - ИРАН}

\author{
Reza Gholi Vahidi ${ }^{1}$, Rahim Khodayari ${ }^{2}$, Shabnam lezadi ${ }^{3}$, Kamal Gholipour ${ }^{4}$
}

Цель. Это исследование было проведено с целью изучения влияния на характеристики пациентов и врачей такого предиктора, как продолжительность пребывания (ПП) пациентов, перенесших коронарное шунтирование.

Материал и методы. Это был ретроспективный анализ, проведенный в Кардиологической клинической Больнице Shaheed Madanee города Тебриза в Иране в 2010 году. Было исследовано 349 пациентов, которые прошли шунтирование в течение 2008-2010 гг. Характеристики пациентов и врачей были извлечены из медицинских записей пациентов с помощью специального контрольного списка, разработанного исследователями. Тест независимых выборок ANOVA проводился для сравнения ПП между категориальными переменными. Данные были проанализированы с использованием статистического пакета SPSS17.

Результаты. Средний возраст пациентов составил 59,7 года. Средняя ПП была 15.58 (10.02) дней. Результаты этого исследования показывают, что пожилые пациенты оставались в больнице в течение гораздо более длительного периода, чем у молодые пациенты. Пребывание пациентов в больнице было статистически значимо и дольше, чем ожидаемой ПП по оценкам врачей

\section{Introduction}

Coronary artery bypass surgery is a safe and accepted technique to treat coronary artery diseases [1], with its own costs implications [2]. The annual cost of it is more than 10 billion US dollars for 500,000 coronary bypass surgeries in the United States [3]. Because of the large number of surgeries performed, even modest reductions in bypass unit cost by rationalizing the length of stay could
$(\mathrm{P}<0,05)$. Пациенты, поступившие в больницу через отделение неотложной помощи, и пациенты без истории госпитализации задерживались в больнице дольше ( $\mathrm{P}=<0.01)$. Ранее выписанные пациенты, а также случаи смерти, также имели длительную ПП ( $\mathrm{P}=<0.01)$. Пациент, чьи лечащие врачи работали в частном секторе, помимо больницы Shaheed Madanee, и имели более высокий уровень образования, оставались дольше, чем те пациенты, чьи врачи работали только в больнице Shaheed Madanee $(\mathrm{P}=<0.01)$.

Заключение. Институциональные характеристики - практика врачей и в частном секторе и в государственной клинической больнице, высокий уровень образования врачей, выполнение требований рекомендаций, и прием протоколов были важными факторами в прогнозировании ПП. История госпитализации пациента, был ли пациент госпитализирован до или после, также является предиктором.

Российский кардиологический журнал 2014, 4 (108), Англ.: 60-63

Ключевые слова: коронарное шунтирование, срок пребывания в больнице.

significantly reduce expenditures at both the hospital and national levels [3].

However it has been shown that length of stay is associated with resource use [4], additionally it is a sensitive and specific marker of inefficiency in using scarce resources of hospitals in inappropriate length of stay [4].

However, there does not appear to be much evidence in the literature to support the assumptions that there is a golden 
standard of length of stay for patients undergoing coronary bypass surgery, but finding of studies indicates that longer preoperative hospital stay can be a risk factor for deep wound infection $[4,5]$, in addition longer preoperative hospital stay was associated with a increased risk of surgical site infections [5]. In recent years, there has been data published from several studies suggesting that the predictors of length of stay as a patient outcome can range from clinical mix $[1,6,7]$, to patient, $[6,8-10]$ and care providers characteristics $[6,8]$. Therefore the risk of prolonged length of stay on patient's outcome may be no different than clinical predictors of patient outcome in regards to service quality. However it seems possible to decrease coronary bypass surgery patients' length of stay with lower resource utilization and costs without adversely affecting patient's outcomes. It is not something out of sight, and it can be achieved with minor interventions in clinical and administrative procedures, processes, providers behaviour, and the guidelines, for instance, some studies show that the development of fast-track anaesthetic techniques for cardiac surgery has helped to decrease intensive care unit (ICU) and hospital length of stay (LOS) without adversely affecting mortality and morbidity $[4,11]$.Therefore this study aimed to study the effect of patients' and physician's characteristics as a predictor in length of stay of patients undergoing coronary artery bypass surgery at Shaheed Madanee Cardiac Teaching Hospital in Tabriz.

\section{Material and methods}

We used a retrospective-observational study at Tabriz Shaheed Madanee Cardiac Teaching Hospital to study 349 hospitalized patients who did undergo a bypass surgery in 2010. About 349 hospitalized patients who did undergo a bypass surgery were studied. Study data were collected using a researcher developed checklist from patient medical records during 2008-2010.

Trained personnel collected data using a standardized checklist on 349 patient's undergone coronary bypass surgery during 2008-2010. Patients in this study had a coronary bypass grafting surgery $(\mathrm{CABG})$ as their principal procedure defined by International Classification of Diseases, Ninth Revision, Clinical Modification (ICD-9-CM) code, according to their medical records. During years 2008-2010 we randomly selected 15 medical records every month out of those records showing that patient has undergone a bypass surgery

Study checklist included demographic information such as: patient's sex, occupation, patients insurance, marital status, type of admission, history of hospitalization, discharge status, physician specialties, physicians practice in private in addition to practice at Shaheed Madanee Hospital sector, and length of stay at the hospital. Furthermore, in regards to determining the assessment of physicians on expected length of stay of patients undergoing coronary bypass surgery data was collected from physicians who had enough experience in diagnosing and performing coronary bypass surgery. The pessimistic, optimistic and most likely length of stay for patients undergo- ing coronary bypass surgery at this hospital were collected though conducting interviews with physicians and then expected length of stay was calculated using the PERT (Program Evaluation and Review Technique) Weighted Average formula:

Expected time $=($ Pessimistic value $+4 *$ most likely value + Optimistic value) $/ 6$

Frequencies and percentages were used to describe demographic information of patients. Independent Samples Test, ANOVA was conducted to compare LOS between categorical variables after testing the normality of their distribution and confirmation by a Kolomogrov-Smirnov test. One-Sample T Test was used to describe the differences between physicians' estimated and actual LOS derived from patients' records. Furthermore data was analyzed using the SPSS17 statistical package. The P values $\leq$ 0.05 were considered as statistically significant.

\section{Results}

Data were collected on all 349 patients undergone coronary bypass surgery. Overall average LOS derived from patients' records was $15.58( \pm 10.02)$ days. The mean age of the patients studied was 59.7 (9.8) years. Further analysis of the data indicates that older patients stayed in the hospital for a significantly longer period than did younger patients ( $P \leq 0.001)$. Table 1 summarizes the findings of the patients' characteristics according to gender, occupation, type of insurance (Insurance plan), mode of admission, history of hospitalization (previous hospitalization due to cardiac problems), discharge status, physicians' educational level, and their practice in private sector.

Study findings indicate females' LOS statistically was longer than male $(p=0.014)$. There was no significant association between length of stay and patients' marital status and place of residence -rural or urban- $(\mathrm{P}>0.05)$. Significant association was observed between length of stay and type of admission and, hospitalization history, and physicians practice in private sector $(\mathrm{P} \leq 0.001)$, also, data related to practice in private sector for two physicians were not available. With the exception discharge status which was a little longer for partial recovery $(\mathrm{P}=0.049)$. Table 1 also reports the length of stay according to physicians status; patients whose physician was a specialist did stay one and half day longer than those whose physician was a sub-specialist, this difference wasn't statistically significant $(\mathrm{P}=0.061)$ (Table 1$)$.

Table 2 indicates detailed pessimistic, optimistic and most likely length of stay according to physician's point of view. To calculate the expected length (time) of stay physicians were asked to estimate pessimistic, optimistic and most likely length of stay for patients undergoing coronary bypass surgery. Then the Expected length (time) of stay was determined using PERT Weighted Average formula.

The physicians estimated LOS was 10.72 days and actual LOS derived from patients' medical records was 15.58 days. The difference between estimated and actual LOS using One-Sample $\mathrm{T}$ Test was statistically significant $(\mathrm{P} \leq 0.05)$ (Table 2 ). 
Table 1

\section{Length of Stay according to Patient and Physician characteristics}

\begin{tabular}{|c|c|c|c|c|}
\hline Characteristics & No $(\%)$ & Mean of Length of Stay (SD) & Min_Max & $p$ \\
\hline \multicolumn{5}{|l|}{ Sex } \\
\hline Male & $246(70)$ & $14.77(8.94)$ & $3-60$ & 0.014 \\
\hline Female & $103(30)$ & $17.53(10.79)$ & $2-71$ & \\
\hline \multicolumn{5}{|l|}{ Occupation } \\
\hline Unemployed & $109(31.1)$ & $17.56(10.82)$ & $2-71$ & 0.052 \\
\hline Employee & $33(14.6)$ & $13(5.77)$ & $6-31$ & \\
\hline Non-Technical worker & $15(8.6)$ & $15.47(9.07)$ & $4-40$ & \\
\hline Retired & $51(4.3)$ & $17.56(10.82)$ & $4-46$ & \\
\hline Farmer & $34(9.7)$ & $15.68(6.41)$ & $3-33$ & \\
\hline Other & $77(22)$ & $14.10(8.56)$ & $3-60$ & \\
\hline \multicolumn{5}{|l|}{ Patient Insurance type } \\
\hline Health services & $170(48.7)$ & $16.16(9.48)$ & $2-60$ & 0.672 \\
\hline Military insurance & $40(11.5)$ & $16.55(8.53)$ & $4-54$ & \\
\hline Private insurance & $8(2.3)$ & $14.50(3.85)$ & $9-20$ & \\
\hline Uninsured & $11(3.1)$ & $14(7.55)$ & $5-27$ & \\
\hline \multicolumn{5}{|l|}{ Patient Marital status } \\
\hline Married & 347 (99.5) & $15.6(9.86)$ & $2-71$ & 0.401 \\
\hline Single & $2(0.5)$ & $13.5(2.27)$ & $6-21$ & \\
\hline \multicolumn{5}{|l|}{ Type of admission } \\
\hline Elective & $261(74.7)$ & $14.11(6.45)$ & $2-60$ & $<0.001$ \\
\hline Emergency & $88(25.3)$ & $19.94(10.54)$ & $2-71$ & \\
\hline \multicolumn{5}{|c|}{ History of hospitalization (previous hospitalization due to cardiac problems) } \\
\hline Yes & $231(66.2)$ & $13.7(9.09)$ & $3-46$ & $<0.001$ \\
\hline No & $118(33.8)$ & $19(7.49)$ & $2-71$ & \\
\hline \multicolumn{5}{|l|}{ Discharge status } \\
\hline Complete recovery & $278(79.7)$ & $14.86(7.59)$ & $2-60$ & 0.049 \\
\hline \multicolumn{5}{|c|}{ Physician's educational status } \\
\hline Specialist & $215(61.6)$ & $15.83(7.24)$ & $3-60$ & 0.061 \\
\hline Sub-Specialists & $134(38.4)$ & $14.35(6.25)$ & $2-46$ & \\
\hline \multicolumn{5}{|c|}{ Physician's work in private sector } \\
\hline Yes & $106(35)$ & $13.45(7.2)$ & $3-60$ & $<0.001$ \\
\hline No & $197(65)$ & $15.97(8.35)$ & $2-71$ & \\
\hline
\end{tabular}

Table 2 characteristics and length of stay in this study. LOS was

\section{Physicians estimated LOS related to real LOS}

\begin{tabular}{|l|l|l|}
\hline Conditions & LOS (day) & $p$ \\
\hline Optimistic & 5.64 & \\
\hline Pessimistic & 20.34 & \\
\hline Most likely & 9.59 & \\
\hline Te. (Expected Time) & 10.72 & $<0.05$ \\
\hline Real LOS according medical record & 15.58 & \\
\hline
\end{tabular}

\section{Discussion}

Previous researchers have found that there is considerable variation in the resource use and LOS associated with bypass surgery. Our study examines the length of stay for a single regional specialist heart hospital in Tabriz. We found substantial associations between patients' and physician's higher for patients, who were unemployed, retired, female, and had no hospitalization history due to cardiac problems, emergency admission patients, and death cases. These findings are generally consistent with prior studies that used medical records identify the predictors of length of stay $[1,2,12]$. Despite previous research findings failure to explain patients and physicians non clinical characteristics [7,13] as predictors of variation of length of stay [1], our findings identify some association between institutional characteristics and length of stay as additional risk factors for prolonged length of stay which are consistent with previous findings $[11,14]$. Length of stay differs due to many factors some of which may be modifiable such as discharge status and physicians practice in private and public sector at the same time $[13,14]$. Therefore variation in pattern of staffing of physicians may affect the length of 
stay $[11,14]$. Research findings indicate that some hospitals adopted protocols to shorten the length of stay, which are being considered to be effective. These studies also revealed that hospital discharge policy, hospital size and managerial factor have a major role in $\operatorname{LOS}[11,13,14]$. Furthermore several recent studies suggest using critical pathways, care maps, and a fast-track protocol is effective to increase the efficiency by reducing LOS $[11,14]$.

Our study provides such information that could be used to predict and distinguish patients who as a result longer period of stay in the hospital. Furthermore, we could determine that savings will be extended if we use integrated hospital and home care services. That is to say, since Shaheed Madanee Hospital is the only hospital serving a vast geographical area (more than three provinces in North West of the country) and most of the residents have difficulty in accessing the post-operative services, the providers and patients tend to prolong the hospital stay. Thereby offering post-operative services through home care can considerably reduce the LOS.

Further research is needed to address these issues, particularly in light of the trend toward shorter hospitalizations and resource utilization without sacrificing the quality of care [15].

On the other hand, due to non-linear pattern of hospital costs and revenue, most of the costs of hospitalization and profitable services for are incurred at the beginning of hospital stay, so, by reducing LOS hospital marginal profit's increase [16]. Along with this factor according to present study findings technical expectancy of LOS based on physician's estimation was significantly shorter than real LOS derived from medical records. In this regard, findings in the literature also indicate that other factors such as quality of care and hospitals volume can influence this issue [17].

Although we tried to limit the constraints of our study but there are still a number of limitations. First, our findings do not take into account the patients' residency and economic characteristics, although, these factors play an enormous role in LOS. In our study context due to lack of access to post-operative services in some setting some patient and provider

\section{References}

1. Nilsson J, Algotsson L, Höglund P, et al. EuroSCORE predicts intensive care unit stay and costs of open heart surgery. Ann Thorac Surg 2004, 78: 1528-34.

2. Maggioni AP, Schweiger C, Tavazzi L, et al. Epidemiologic study of use of resources in patients with unstable angina: The EARISA Registry. American Heart Journal 2000, 140: 253-63.

3. Cowper PA, DeLong ER, Peterson ED, $\mathrm{H}$ et al. Variability in cost of coronary bypass surgery in New York State: Potential for cost savings. American Heart Journal 2002, 143: 130-9.

4. Bordalo A, Nobre A, Mendes M, et al. Advantages of off-pump coronary bypass surgery over conventional coronary bypass surgery. Rev Port Cir Cardiotorac Vasc 201017: 217-28.

5. Ng CY, Ramli MF, Awang Y. Coronary bypass surgery in patients aged 70 years and over: mortality, morbidity, length of stay and hospital cost. Asian Cardiovasc Thorac Ann 2004, 12: 218-23.

6. Smith ID, Elton R, Ballantyne JA, et al. Pre-operative predictors of the length of hospital stay in total knee replacement. J Bone Joint Surg Br 2008, 90: 1435-40.

7. Najafi M, Goodarzynejad H. Determinants of length of stay in surgical ward after coronary bypass surgery: glycosylated hemoglobin as a predictor in all patients, diabetic or non-diabetic. J Tehran Heart Cent 2012, 7: 170-6.

8. Husted H, Holm G, Jacobsen S. Predictors of length of stay and patient satisfaction after hip and knee replacement surgery: fast-track experience in 712 patients. Acta Orthop Apr 2008, 79 : 168-73.

9. Batsis JA, Naessens JM, Keegan MT, et al. Body mass index and the impact on hospital resource use in patients undergoing total knee arthroplasty. J Arthroplasty 2010, 25: 1250-7. prefer to longer LOS. Second, to be as an observational and retrospective study, the results were subject to documentation biases and missing data Third, We also had no access to and did not follow up transfer patients, thereby have no idea of their LOS. Fourth, we did not mention the other factor such as patient's co-morbidities and surgery condition that may influence LOS, due to incomplete medical records.

In summary, this research suggests that provider's characteristics - physician's practice both in private sector and public teaching hospital, discharge process guidelines, and admission protocols- were substantial predictors of length of stay. Patient non clinical characteristics such as gender, occupation, type of insurance and marital status did not play an important role in hospital stay except hospitalization history - those with no hospitalization history stayed for longer period. Furthermore the data from this study may be useful to administrators and physicians who are involved in the management of health programmers and hospital budget, to encourage shorter length of stay to reduce costs. Further research is needed to assess its impact on patient outcomes.

\section{Conclusion}

The factors that were significantly associated with length of stay were largely due to institutional characteristics - physicians practice both in private sector and public teaching hospital, physicians' level of education (specialist, subspecialist), discharge process guidelines, and admission protocols. The patient's hospitalization history was also a predictor (those with no hospitalization history stayed longer). The shorter length of stay seemed to be possible by administrative interventions to normalize the potential institutional predictors.

\section{Acknowledgements}

We would like to acknowledge the co-operation of all the cardiac surgeons at the Shaheed Madanee Teaching Hospital. We would also like to thank chairman cardiology and thorax department for their support in conducting this study.

10. Miric A, Lim M, Kahn B, et al.Perioperative morbidity following total knee arthroplasty among obese patients. J Knee Surg 2002, 15: 77-83.

11. Epestain AM, Jha AK, Orav EJ. The Relationship between Hospital Admission Rates and Rehospitalizations. N Engl J Med 2011, 365: 2287-95.

12. De-Hert SG, Van-der-Linden PJ, Cromheecke S, et al. Choice of Primary Anesthetic Regimen Can Influence Intensive Care Unit Length of Stay after Coronary Surgery with Cardiopulmonary Bypass. Anesthesiology 2004, 101: 9-20.

13. LiY, Cai X, Mukamel DB, et al. Impact of length of stay after coronary bypass surgery on shortterm readmission rate: an instrumental variable analysis. Med Care 2013, 51: 45-51.

14. Claeys M.J, Sinnaeve PR, Convens C, et al. Inter-hospital variation in length of hospital stay after ST-elevation myocardial infarction: results from the Belgian STEMI registry. Acta Cardiologica 2013, 68: 235-9

15. Glance LG, Osler TM, Mukamel DB, et al. Estimating the potential impact of regionalizing health care delivery based on volume standards versus risk-adjusted mortality rate. Int J Qual Health Care 2007, 19: 195-202.

16. Taheri PA, Butz DA, Greenfield LJ. Length of stay has minimal impact on the cost of hospital admission. J Am Coll Surg 2000, 191:123-30.

17. Auerbach $\mathrm{AD}$, Hilton JF, Maselli $\mathrm{J}$, et al. Case volume, quality of care, and care efficiency in coronary artery bypass surgery. Arch Intern Med 2010170: 1202-8. 